\title{
Association between Kidney Function and Telomere Length: The Heart and Soul Study
}

\author{
Nisha Bansal $^{\mathrm{a}}$ Mary A. Whooley ${ }^{\mathrm{a}, \mathrm{b}, \mathrm{e}}$ Mathilda Regan $^{\mathrm{e}}$ Charles E. McCulloch $^{\mathrm{b}}$ \\ Joachim H. Ix ${ }^{f-h}$ Elissa Epel ${ }^{c}$ Elizabeth Blackburn ${ }^{d}$ Jue Lin ${ }^{d}$ Chi-yuan Hsu ${ }^{a}$ \\ Departments of a Medicine, ${ }^{b}$ Epidemiology and Biostatistics, ${ }^{c}$ Psychiatry and ${ }^{d}$ Biochemistry and Biophysics, \\ University of California, ' San Francisco Veterans Affairs Medical Center, San Francisco, Calif., ${ }^{f}$ Nephrology Section, \\ Veterans Affairs San Diego Healthcare System, and ${ }^{9}$ Division of Nephrology, Department of Medicine, and \\ hDivision of Preventative Medicine, Department of Family and Preventative Medicine, University of California, \\ San Diego, Calif., USA
}

\section{Key Words}

Kidney $\cdot$ Chronic kidney disease $\cdot$ Telomere

\begin{abstract}
Background: Telomere attrition is a novel risk factor for cardiovascular disease. Studies of telomere length in relation to kidney function are limited. We explored the association of kidney function with telomere length and telomere shortening. Methods: The Heart and Soul Study is a longitudinal study of patients with stable coronary heart disease. Measures of baseline kidney function included: serum creatinine, creatinine-derived estimated glomerular filtration rate

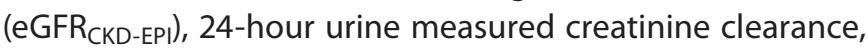
cystatin C, cystatin C-derived estimated glomerular filtration rate (eGFRcys) and urine albumin to creatinine ratio. Telomere length was measured from peripheral blood leukocytes at baseline $(n=954)$ and 5 years later $(n=608)$. Linear regression models were used to test the association of kidney function with (i) baseline telomere length and (ii) change in telomere length over 5 years. Results: At baseline, mean eGFR $_{\text {CKD-EPI }}$ was $72.6( \pm 21.5) \mathrm{ml} / \mathrm{min} / 1.73 \mathrm{~m}^{2}$, eGFRcys was $71.0( \pm 23.1) \mathrm{ml} / \mathrm{min} / 1.73 \mathrm{~m}^{2}$ and ACR was $8.6( \pm 12.3) \mathrm{mg} / \mathrm{g}$. Only lower baseline eGFR $\mathrm{CKD}_{\text {-EPI }}$ was associated with shorter
\end{abstract}

baseline telomere length $(9.1$ ( $95 \% \mathrm{Cl}$ 1.2-16.9) fewer base pairs for every $5 \mathrm{ml} / \mathrm{min} / 1.73 \mathrm{~m}^{2}$ lower eGFR (KD-EPI). Lower

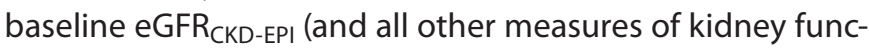
tion) predicted more rapid telomere shortening $(10.8$ (95\% $\mathrm{Cl}$ 4.3-17.3) decrease in base pairs over 5 years for every $5 \mathrm{ml} /$

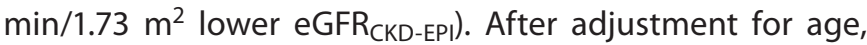
these associations were no longer statistically significant. Conclusions: In patients with coronary heart disease, reduced kidney function is associated with (i) shorter baseline telomere length and (ii) more rapid telomere shortening over 5 years; however, these associations are entirely explained by older age.

Copyright $\odot 2012$ S. Karger AG, Basel

\section{Introduction}

Telomere length is a novel biomarker of physiologic age and cardiovascular risk. Telomeres are random repeat DNA sequences that form a protective cap at the ends of eukaryotic chromosomes [1]. The role of telomeres is to prevent chromosome ends from being identified as double-strand breaks in DNA, thus limiting chromosome shortening and recombination. With natural

\section{KARGER}

Fax +41613061234

E-Mail karger@karger.ch

www.karger.com
(C) 2012 S. Karger AG, Basel

0250-8095/12/0365-0405\$38.00/0

Accessible online at:

www.karger.com/ajn
Nisha Bansal, MD, MAS

Division of Nephrology, University of California, San Francisco

521 Parnassus Ave, Box 0532

San Francisco, CA 94143 (USA)

E-Mail nisha.bansal@ucsf.edu 
aging, DNA polymerase is not able to fully replicate the $3^{\prime}$ end of linear DNA, resulting in an obligate and progressive loss of telomere repeats with each cell division - eventually resulting in cellular senescence or apoptosis $[2,3]$. Chronic diseases may accelerate this process, leading to premature telomere attrition.

Clinical studies have reported that patients with endstage renal disease (ESRD) may have shorter telomere length and accelerated telomere shortening compared with the general population $[4,5]$. Studies of severe heart failure patients have reported a strong correlation between reduced kidney function and shorter telomere length, even after adjustment for age $[6,7]$.

It is possible that chronic kidney disease (CKD) is related to shorter telomere length, and that shorter telomere length may identify individuals with reduced kidney function at highest risk for adverse outcomes. Also, it is possible that persons with decreased kidney function have more rapid telomere shortening over time; however, to our knowledge, no prior study has evaluated these questions. The Heart and Soul Study, a cohort of participants with stable coronary heart disease and kidney function ranging from normal to moderate CKD, provides a unique platform to study kidney function and telomere length. Previous studies in Heart and Soul have shown that both shorter telomere length and reduced kidney function are associated with all-cause mortality $[8,9]$. In this study, we aimed to test the association of six different measures of kidney function with telomere length and telomere shortening over 5 years.

\section{Methods}

\section{Study Design and Participants}

The Heart and Soul Study is an observational study designed to investigate the influence of psychosocial factors on the progression of coronary heart disease. Methods have been described previously [10]. Briefly, participants were recruited from outpatient clinics in the San Francisco Bay area if they met one of the following inclusion criteria: history of myocardial infarction, angiographic evidence of $>50 \%$ stenosis in $\geq 1$ coronary vessels, evidence of exercise-induced ischemia by treadmill or nuclear testing, history of coronary revascularization, or documented diagnosis of coronary heart disease by an internist or cardiologist. Participants were excluded if they were not able to walk 1 block, had experienced myocardial infarction within the past 6 months, or were likely to move out of the area within 3 years. The study protocol was approved by the institutional review boards of participating institutions, and all participants provided written informed consent. Between September 2000 and December 2002, 1,024 participants enrolled and underwent a day-long baseline study appointment that included a medical history, physical ex- amination, and comprehensive health status questionnaire. Outpatient 24-hour timed urine collections and fasting (12-hour) morning venous blood samples were obtained at baseline. Longitudinal follow-up for the Heart and Soul Study is still ongoing.

\section{Measures of Kidney Function}

All Heart and Soul participants were eligible for our study, regardless of baseline renal function. We evaluated six measures of kidney function: serum creatinine, creatinine-derived estimated glomerular filtration rate (GFR) (eGFR $\left.\mathrm{CKD}_{\text {-EPI }}\right)$, creatinine clearance $(\mathrm{CrCl})$, serum cystatin $\mathrm{C}$, cystatin $\mathrm{C}$-derived estimated GFR (eGFRcys) and urine albumin to creatinine ratio. Serum creatinine was measured by the rate Jaffe method (mg/dl). eGFR CKD-EPI $_{\text {. }}$ was calculated using serum creatinine [11]. $\mathrm{CrCl}$ was measured from 24-hour urine collections by protocol that has been described previously [12]. In brief, participants received detailed instructions on accurate urine collection and specimen refrigeration. Subjects were asked to void at the end of their study appointment and to begin the collection from that point forward. Research personnel arrived at the patient's home $24 \mathrm{~h}$ after the timed collection was initiated to avoid over- or undercollection. If participants reported missing any urine or collections were $<1$ or $>3$ liters, collections were repeated. When participants were unable to collect all urine for any reason, no data were recorded. Urine volume was recorded $(\mathrm{ml})$, and creatinine was measured by the rate Jaffe method. $\mathrm{CrCl}$ was calculated by urine creatinine $\times$ urine volume/serum creatinine $\times 1,440$ and expressed as $\mathrm{ml} /$ min. Cystatin $\mathrm{C}$ was measured from frozen samples collected at the baseline study visit with the use of a BNII nephelometer (Dade Behring, Inc., Deerfield, Ill., USA) with a particle-enhanced immunonephelometric assay (N Latex Cystatin C; Dade Behring, Inc.) [13]. The intra-assay coefficient of variation (CV) was 2.0$2.8 \%$ and the inter-assay CV was $2.3-3.1 \%$. Serum cystatin C was log-transformed for all analyses given the skewed distribution. GFR was estimated using cystatin $\mathrm{C}$ with the formula: eGFRcys = $76.7 \times$ cystatin $C^{-1.19}[14]$. Urinary albumin and creatinine were measured by nephelometry and the rate Jaffe method, respectively. A urine albumin to creatinine ratio was calculated in $\mathrm{mg} / \mathrm{g}$ and log-transformed given the skewed distribution.

\section{Measurement of Telomere Length}

Our study outcomes were: (1) telomere length at baseline and (2) change in telomere length from baseline to year 5. Baseline DNA samples were not available for 70 of the 1,024 study participants, so telomere length was measured in 954 participants. Of these, 608 participants ( $>80 \%$ of survivors) had a repeat measurement after 5 years.

At both visits, genomic DNA was isolated according to standard procedures from peripheral blood leukocytes and stored at $-70^{\circ} \mathrm{C}$. Purified DNA samples were diluted in 96-well microtiter source plates to a fixed concentration of $3 \mathrm{ng} / \mu \mathrm{l}$ [15]. Telomere length was measured by a quantitative polymerase chain reaction (qPCR) assay that compares mean telomere repeat sequence copy number $(\mathrm{T})$ to a reference single-copy gene copy number $(\mathrm{S})$ in each sample and validated by comparison with Southern blot terminal restriction fragment analysis [16]. All PCRs were carried out on a Roche LightCycler 480 real-time PCR machine (Roche Applied Science, Indianapolis, Ind., USA) [15].

Telomere length was measured in $\mathrm{T} / \mathrm{S}$ ratio units. The relative quantity of the single-copy gene (S) in each experimental sample 
was expressed as the level of dilution of the reference DNA sample needed to match it to the experimental sample with regard to the number of cycles of PCR needed to generate a given amount of single-copy gene PCR product during the exponential phase of the PCR (T). For each experimental sample the ratio of these dilution factors is the relative telomere to single-copy gene (T/S) ratio [16]. Thus T/S = 1 when the unknown DNA is identical to the reference DNA in its ratio of telomere repeat copy number $(\mathrm{T})$ to single-copy gene copy number (S). The reference DNA sample (to which all of the experimental samples in a given study are compared) was from a pooled sample from multiple individuals. The $\mathrm{T} / \mathrm{S}$ ratio of one individual relative to the T/S ratio of another should correspond to the relative telomere lengths of their DNA. The $\mathrm{T} / \mathrm{S}$ ratio was measured twice in each individual at each time point, and results were averaged. When the duplicate T/S value and the initial value differed by more than $7 \%$, the sample was run for a third time and the two closest values were used to calculate the mean. Approximately $15 \%$ of the samples required assay in triplicate. Using this method, we observed inter-assay CV for telomere length measurement is $3.7 \%$ and the intra-assay $\mathrm{CV}$ is $2.5 \%$ [15]. Similar to other analyses within Heart and Soul, we converted the T/S ratio to base pairs using the formula: base pairs $=3,274$ $+2,413 \times(\mathrm{T} / \mathrm{S})[17]$.

\section{Covariates}

All covariates were taken from the baseline study visit and examination. Demographics (age, sex and race) and medical history (history of smoking, hypertension, diabetes, heart failure, myocardial infarction or stroke) were determined by questionnaire. Participants underwent a complete physical examination that included blood pressure determination by trained study personnel using calibrated sphygmomanometers. Body mass index was calculated by measured weight $(\mathrm{kg})$ divided by height $(\mathrm{m})$ squared. Participants were instructed to bring their medication bottles to the study appointment, and study personnel recorded all current medications, including aspirin, $\beta$-blockers, angiotensin-converting enzymes (ACE) inhibitors and angiotensin receptor blockers (ARBs).

High-sensitivity C-reactive protein was measured with the use of the Roche Integra assay and the Beckman Extended Range assay as previously described [9] and was log-transformed for this analysis. Fasting serum samples were used to measure total cholesterol, high-density lipoprotein (HDL) cholesterol, and triglyceride concentrations. Low-density lipoprotein (LDL) cholesterol concentrations were calculated using the Friedewald equation [18].

\section{Statistical Methods}

We compared baseline characteristics of participants across quartiles of baseline telomere length using t tests and ANOVA as appropriate. We then used linear regression to explore the crosssectional association between each of the six measures of kidney function and telomere length at baseline, first in unadjusted analyses and then adjusted for age. Prior work has shown that baseline telomere length is strongly associated with subsequent change in telomere length [17]. Therefore, we calculated a change score that was adjusted for baseline telomere length by performing linear regression to examine the association between baseline telomere length and change in telomere length. The residual from the model was used as the outcome variable in subsequent models in which we then examined the association between measures of kidney function and change in telomere length over 5 years (in unadjusted analyses and then in models adjusted for age).

All analyses were conducted using SAS (Cary, N.C., USA) and $p$ values $<0.05$ were considered evidence of statistical significance.

\section{Results}

Among the 954 participants with telomere measures at baseline, mean age was $66.7( \pm 11.0)$ years, $18.6 \%$ were female and $16.5 \%$ were Black. Mean serum creatinine was $1.1( \pm 0.7) \mathrm{mg} / \mathrm{dl}, \mathrm{eGFR}_{\mathrm{CKD} \text {-EPI }}$ was $72.6( \pm 21.5) \mathrm{ml} /$ $\mathrm{min} / 1.73 \mathrm{~m}^{2}, \mathrm{CrCl}$ was $92.3( \pm 35.9) \mathrm{ml} / \mathrm{min}$, cystatin $\mathrm{C}$ was $1.20( \pm 0.56) \mathrm{mg} / \mathrm{l}$, eGFRcys was $71.0( \pm 23.1) \mathrm{ml} /$ $\min / 1.73 \mathrm{~m}^{2}$, and urine albumin to creatinine ratio was $8.6( \pm 12.3) \mathrm{mg} / \mathrm{g}$. Mean baseline telomere length was $5,444.502( \pm 529.34)$ base pairs. The ranges for the quartiles of baseline telomere length were as follows: quartile 1 (4,294-5,062 base pairs), quartile 2 (5,065-5,388 base pairs), quartile $3(5,391-5,778$ base pairs) and quartile 4 (5,779-7,470 base pairs). Those with the shortest telomere length at baseline were older, less likely to be Black, more likely to have a history of stroke and were less likely to be taking aspirin (table 1).

There was no association between serum creatinine, $\mathrm{CrCl}$, cystatin $\mathrm{C}$, eGFRcys or albuminuria and quartile of baseline telomere length in cross-sectional analyses (table 2). When entered as continuous variables,

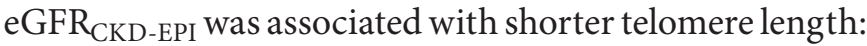
for every $5 \mathrm{ml} / \mathrm{min} / 1.73 \mathrm{~m}^{2}$ lower eGFR $\mathrm{CKD}_{\mathrm{EPI}}$, there were 9.1 fewer base pairs (95\% CI 1.2-16.9, $\mathrm{p}=0.02)$. However, this association was no longer statistically significant after adjustment for age (table 3 ).

In longitudinal analyses, higher serum creatinine, lower $\mathrm{CrCl}$, lower eGFR $\mathrm{CKD}_{\text {-EPI}}$, higher cystatin $\mathrm{C}$ and lower eGFRcys were all associated with greater telomere shortening over 5 years (table 4). Again, after adjustment for age, these associations were no longer statistically significant.

\section{Discussion}

Leukocyte telomere length has emerged as a novel cardiovascular risk factor in the general population and is associated with a poor prognosis among patients with existing coronary heart disease. However, the relationship of telomere length and kidney function remains unexplored and may be an important contributor to adverse 
Table 1. Baseline characteristics of study population by baseline telomere length $(\mathrm{n}=954)^{1}$

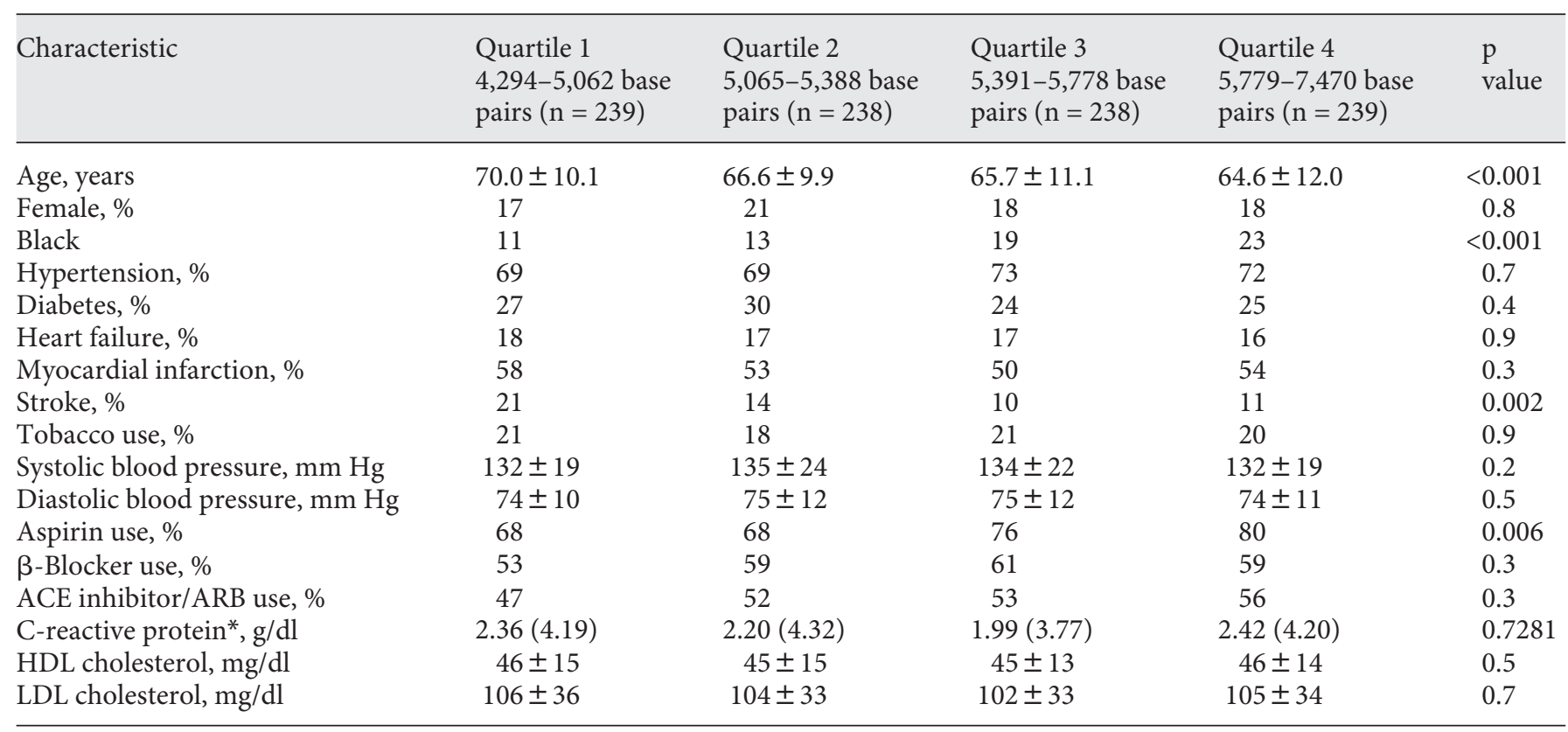

${ }^{1}$ Reported as mean $\pm \mathrm{SD}$, unless otherwise specified.

* Median (IQR).

Table 2. Baseline measures of kidney function by baseline telomere length $(\mathrm{n}=954)^{1}$

\begin{tabular}{|c|c|c|c|c|c|}
\hline Measure of kidney function & $\begin{array}{l}\text { Quartile } 1 \\
4,294-5,062 \text { base } \\
\text { pairs }(n=239)\end{array}$ & $\begin{array}{l}\text { Quartile } 2 \\
5,065-5,388 \text { base } \\
\text { pairs }(n=238)\end{array}$ & $\begin{array}{l}\text { Quartile } 3 \\
5,391-5,778 \text { base } \\
\text { pairs }(n=238)\end{array}$ & $\begin{array}{l}\text { Quartile } 4 \\
5,779-7,470 \text { base } \\
\text { pairs }(n=239)\end{array}$ & $\mathrm{p}$ value \\
\hline Urine $\mathrm{CrCl}, \mathrm{ml} / \mathrm{min} / 1.73 \mathrm{~m}^{2}$ & $88.8 \pm 36.4$ & $94.0 \pm 36.4$ & $91.7 \pm 35.0$ & $94.6 \pm 35.7$ & 0.3 \\
\hline $\mathrm{eGFR}_{\mathrm{CKD} \text {-EPI }}, \mathrm{ml} / \mathrm{min} / 1.73 \mathrm{~m}^{2}$ & $70.2 \pm 21.4$ & $73.5 \pm 20.1$ & $72.7 \pm 21.6$ & $74.1 \pm 22.6$ & 0.2 \\
\hline Urine albumin to creatinine ratio, $\mathrm{mg} / \mathrm{g}^{*}$ & $8.4(12.1)$ & $9.4(13.7)$ & $9.1(12.2)$ & $8.1(10.3)$ & 0.3 \\
\hline
\end{tabular}

${ }^{1}$ Reported as mean $\pm \mathrm{SD}$, unless otherwise specified.

* Median (IQR).

cardiovascular outcomes among patients with CKD. We found that patients with decreased kidney function had greater shortening of telomere length over 5 years. However, after adjustment for age, this association was no longer significant. These findings suggest that telomere shortening and worsening kidney function are parallel processes that occur with aging.

We found that patients with decreased kidney function had greater shortening of telomere length over 5 years. However, after adjustment for age, this association was no longer significant, consistent with natural aging confounding this relationship. There is great interest in studying telomere length in kidney health $[19,20]$; however, clinical studies are limited. Previous studies have suggested that telomere length is shorter in patients with ESRD on dialysis compared with the general population. For example, in a study of 15 hemodialysis patients and 15 age-matched controls, the authors found accelerated 
Table 3. Cross-sectional association between baseline measures of kidney function and baseline telomere length $(\mathrm{n}=954)$

\begin{tabular}{|c|c|c|}
\hline Measure of kidney function & $\begin{array}{l}\text { Unadjusted } \\
\beta \text {-coefficient (95\% CI) }\end{array}$ & $\begin{array}{l}\text { Adjusted for age } \\
\beta \text {-coefficient }(95 \% \mathrm{CI})\end{array}$ \\
\hline Serum creatinine (per $1 \mathrm{mg} / \mathrm{dl}$ increase) & $1.0(-50.9,52.9)$ & $8.6(-42.5,59.7)$ \\
\hline $\mathrm{CrCl}$ (per $5 \mathrm{ml} / \mathrm{min}$ decrease) & $-3.8(-8.7,1.0)$ & $1.7(-3.5,7.0)$ \\
\hline $\mathrm{eGFR}_{\text {CKD-EPI }}\left(\right.$ per $5 \mathrm{ml} / \mathrm{min} / 1.73 \mathrm{~m}^{2}$ decrease) & $-9.1^{*}(-16.9,-1.2)$ & $1.6(-7.1,10.3)$ \\
\hline $\log$ cystatin C (per log mg/l increase) & $-69.2(-174.3,36.0)$ & $12.0(-95.5,119.4)$ \\
\hline eGFRcys (per $5 \mathrm{ml} / \mathrm{min} / 1.73 \mathrm{~m}^{2}$ decrease) & $-3.7(-11.0,3.7)$ & $3.3(-4.3,10.9)$ \\
\hline \multicolumn{3}{|l|}{ log urine albumin to creatinine ratio (per } \\
\hline $\log \mathrm{mg} / \mathrm{g}$ increase) & $-14.8(-39.7,10.1)$ & $-8.1(-32.8,16.6)$ \\
\hline
\end{tabular}

Coefficients represent change in number of base pairs for each unit of worsening kidney function.

${ }^{*} \mathrm{p}<0.05$.

Table 4. Longitudinal association between baseline measures of kidney function and change in telomere length over 5 years (from baseline to year 5$)(n=608)$

\begin{tabular}{|c|c|c|}
\hline Measure of kidney function & $\begin{array}{l}\text { Unadjusted } \\
\beta \text {-coefficient (95\% CI) }\end{array}$ & $\begin{array}{l}\text { Adjusted for age } \\
\beta \text {-coefficient }(95 \% \mathrm{CI})\end{array}$ \\
\hline Serum creatinine (per $1 \mathrm{mg} / \mathrm{dl}$ increase) & $-47.8^{*}(-93.3,-2.2)$ & $-42.1(-85.8,1.7)$ \\
\hline $\mathrm{CrCl}$ by 24 -hour urine collection (per $5 \mathrm{ml} / \mathrm{min}$ decrease) & $-3.6^{*}(-7.8,-0.1)$ & $1.2(-2.8,5.1)$ \\
\hline $\mathrm{eGFR}_{\text {CKD-EPI }}\left(\right.$ per $5 \mathrm{ml} / \mathrm{min} / 1.73 \mathrm{~m}^{2}$ decrease $)$ & $-10.8^{*}(-17.3,-4.3)$ & $-0.4(-7.4,6.7)$ \\
\hline $\log$ cystatin $C$ (per log mg/l increase) & $-139.8^{*}(-231.1,-48.6)$ & $-54.6(-146.2,37.1)$ \\
\hline eGFRcys (per $5 \mathrm{ml} / \mathrm{min} / 1.73 \mathrm{~m}^{2}$ decrease) & $-9.7^{*}(-15.5,-3.9)$ & $-3.4(-9.4,2.5)$ \\
\hline \multicolumn{3}{|l|}{ log urine albumin to creatinine ratio (per } \\
\hline $\log \mathrm{mg} / \mathrm{g}$ increase) & $-6.9(-28.5,14.7)$ & $-5.4(-26.1,15.4)$ \\
\hline
\end{tabular}

Coefficients represent change in number of base pairs associated with each unit of worsening kidney function; positive coefficient represents telomere lengthening; negative coefficient represents telomere shortening. ${ }^{*} \mathrm{p}<0.05$.

telomere shortening in the dialysis patients [21]. Another study of 18 diabetic dialysis patients and 20 controls found an inverse correlation between telomere length and length of time on dialysis [4]. A study of 42 hemodialysis patients found that telomerase activity was reduced compared with non-hemodialysis patients [5]. There are very limited data on the associations between telomere length and kidney function among persons with less severe kidney disease. Similar to our results, a study of older adults in the Cardiovascular Health Study reported no association between telomere length and cystatin $\mathrm{C}$ after adjustment for age, gender and race [22]. Previous studies of heart failure patients with normal kidney function reported a strong correlation between reduced kidney function and shorter telomere length, even after adjustment for age $[6,7]$. Our results differ from these prior studies suggesting that associations between kidney function and telomere shortening are entirely explained by age. However, these studies evaluated persons with decreased ejection fraction and also relied solely on creatinine-based measurements of kidney function. Our study added to previous studies by examining multiple markers of renal function. In particular, studies of sicker (such as heart failure) or elderly patients may misclassify level of kidney function if they rely on creatinine-based measures of kidney function alone. While our results differed from the prior studies of ESRD and heart failure patients, they were consistent with the results of the study of older adults. Further studies are needed to elucidate if telomere biology differs in varying patient populations.

Our findings have implications in the study of cardiovascular risk in patients with CKD. In the general popu- 
lation, shortened telomere length has emerged as a novel risk factor linked to higher rates of cardiovascular disease and mortality. For example, in a nested case-control study of middle-aged high-risk men, the risk of coronary heart disease was almost double in those in the lower two tertiles of telomere length compared with those in the highest tertile [23]. Another study of 1,136 older participants in the Cardiovascular Health Study found that persons with the shortest quartile of telomere length were more likely to die of any cause compared with persons in the highest quartile [24]. A few studies have also suggested that reduced telomere length is associated with mortality among dialysis patients as well. One study of 175 prevalent hemodialysis patients found that reduced telomere length was associated with mortality even after adjustment for age, gender and inflammation [25]. However, our study suggests that accelerated telomere shortening is unlikely to contribute to the high burden of morbidity and mortality among patients with decreased kidney function (not on dialysis) independent of other risk factors such as advanced age.

Our study had several strengths. We studied a relatively large, well-characterized cohort of patients with stable coronary heart disease. We had six unique urine and serum markers of kidney function. We utilized a large cohort with measures of telomere length, many of whom had repeat measures of telomere length after 5 years. Our study also has important limitations. Of the participants with kidney disease, most had mild to moderate $\mathrm{CKD}$, low levels of proteinuria, and well-controlled hypertension, and therefore our results may not be generalizable to a population with advanced stages of CKD due to diabetic nephropathy or glomerulonephritis. Par- ticipants were older, mostly male and had stable coronary heart disease. Results may differ in other populations. Telomere length was measured from peripheral leukocytes rather than directly in renal tubular cells. However, this is a commonly used measure of telomere length in clinical studies and widespread renal biopsies are neither practical nor ethical to carry out.

In conclusion, we found that decreased kidney function was not independently associated with shortened telomere length or telomere shortening over 5 years. Further longitudinal clinical studies evaluating other novel factors linked with both decreased kidney function and cardiovascular disease are needed to explore mechanisms linking these two highly prevalent and morbid conditions.

\section{Acknowledgements}

This study was supported by grants from the National Institute of Diabetes and Digestive and Kidney Diseases (K23 DK088865 to N.B. and K24 DK92291 to C.H.), National Heart Lung and Blood Institute (1R01HL096851) (J.H.I.), an American Heart Association Fellow-to-Faculty Transition Award (J.H.I.), and an award from the Sandra Daugherty Foundation (J.H.I.). The Heart and Soul Study was funded by the Department of Veterans Affairs, American Federation of Aging Research, Robert Wood Johnson Foundation, Nancy Kirwan Heart Research Fund, Ischemia Research and Education Foundation, and the NHLBI (R01 HL079235).

\section{Disclosure Statement}

The authors have no conflicts of interest to disclose.

\section{References}

1 Blackburn EH: Switching and signaling at the telomere. Cell 2001:106:661-673.

2 Blackburn EH: Structure and function of telomeres. Nature 1991;350:569-573.

-3 Olovnikov AM: Telomeres, telomerase, and aging: origin of the theory. Exp Gerontol 1996;31:443-448.

4 Boxall MC, Goodship TH, Brown AL, Ward $\mathrm{MC}$, von Zglinicki T: Telomere shortening and haemodialysis. Blood Purif 2006;24:185-189.

5 Tsirpanlis G, Chatzipanagiotou S, Boufidou F, Kordinas V, Alevyzaki F, Zoga M, Kyritsis I, Stamatelou K, Triantafyllis G, Nicolaou C: Telomerase activity is decreased in peripheral blood mononuclear cells of hemodialysis patients. Am J Nephrol 2006;26:91-96.
-6 Van der Harst P, Wong LS, de Boer RA, Brouilette SW, van der Steege G, Voors AA, Hall AS, Samani NJ, Wikstrand J, van Gilst WH, van Veldhuisen DJ: Possible association between telomere length and renal dysfunction in patients with chronic heart failure. Am J Cardiol 2008;102:207-210.

7 Wong LS, van der Harst P, de Boer RA, Codd V, Huzen J, Samani NJ, Hillege HL, Voors AA, van Gilst WH, Jaarsma T, van Veldhuisen DJ: Renal dysfunction is associated with shorter telomere length in heart failure. Clin Res Cardiol 2009;98:629-634.

-8 Farzaneh-Far R, Cawthon RM, Na B, Browner WS, Schiller NB, Whooley MA: Prognostic value of leukocyte telomere length in pa- tients with stable coronary artery disease: data from the Heart and Soul Study. Arterioscler Thromb Vasc Biol 2008;28:1379-1384.

9 Ix JH, Shlipak MG, Chertow GM, Whooley MA: Association of cystatin $\mathrm{C}$ with mortality, cardiovascular events, and incident heart failure among persons with coronary heart disease: data from the Heart and Soul Study. Circulation 2007;115:173-179.

10 Whooley MA, de Jonge P, Vittinghoff E, Otte C, Moos R, Carney RM, Ali S, Dowray S, Na B, Feldman MD, Schiller NB, Browner WS: Depressive symptoms, health behaviors, and risk of cardiovascular events in patients with coronary heart disease. JAMA 2008;300: 2379-2388. 
11 Levey AS, Stevens LA, Schmid CH, Zhang YL, Castro AF 3rd, Feldman HI, Kusek JW, Eggers P, Van Lente F, Greene T, Coresh J: A new equation to estimate glomerular filtration rate. Ann Intern Med 2009;150:604612.

12 Ix JH, de Boer IH, Wassel CL, Criqui MH, Shlipak MG, Whooley MA: Urinary creatinine excretion rate and mortality in persons with coronary artery disease: the Heart and Soul Study. Circulation 2010;121:1295-1303.

13 Erlandsen EJ, Randers E, Kristensen JH: Evaluation of the Dade Behring N Latex Cystatin $\mathrm{C}$ assay on the Dade Behring Nephelometer II system. Scand J Clin Lab Invest 1999;59:1-8.

14 Stevens LA, Coresh J, Schmid CH, Feldman HI, Froissart M, Kusek J, Rossert J, Van Lente F, Bruce RD 3rd, Zhang YL, Greene T, Levey AS: Estimating GFR using serum cystatin C alone and in combination with serum creatinine: a pooled analysis of 3,418 individuals with CKD. Am J Kidney Dis 2008;51: 395-406.

15 Farzaneh-Far R, Lin J, Epel ES, Harris WS, Blackburn EH, Whooley MA: Association of marine omega-3 fatty acid levels with telomeric aging in patients with coronary heart disease. JAMA 2010;303:250-257.
16 Cawthon RM: Telomere measurement by quantitative PCR. Nucleic Acids Res 2002; 30:e47.

17 Farzaneh-Far R, Lin J, Epel E, Lapham K, Blackburn E, Whooley MA: Telomere length trajectory and its determinants in persons with coronary artery disease: longitudinal findings from the Heart and Soul Study. PLoS One 2010;5:e8612.

18 Friedewald WT, Levy RI, Fredrickson DS: Estimation of the concentration of low-density lipoprotein cholesterol in plasma, without use of the preparative ultracentrifuge. Clin Chem 1972;18:499-502.

19 Westhoff JH, Schildhorn C, Jacobi C, Homme M, Hartner A, Braun H, Kryzer C, Wang C, von Zglinicki T, Kranzlin B, Gretz N, Melk A: Telomere shortening reduces regenerative capacity after acute kidney injury. J Am Soc Nephrol 2010;21:327-336.

20 Song J, Czerniak S, Wang T, Ying W, Carlone DL, Breault DT, Humphreys BD: Characterization and fate of telomerase-expressing epithelia during kidney repair. J Am Soc Nephrol 2011;22:2256-2265.

21 Ramirez R, Carracedo J, Soriano S, Jimenez R, Martin-Malo A, Rodriguez M, Blasco M, Aljama P: Stress-induced premature senescence in mononuclear cells from patients on long-term hemodialysis. Am J Kidney Dis 2005;45:353-359.
22 Sanders JL, Fitzpatrick AL, Boudreau RM, Arnold AM, Aviv A, Kimura M, Fried LF, Harris TB, Newman AB: Leukocyte telomere length is associated with noninvasively measured age-related disease: the Cardiovascular Health Study. J Gerontol A Biol Sci Med Sci 2012;67:409-416.

- 23 Brouilette SW, Moore JS, McMahon AD, Thompson JR, Ford I, Shepherd J, Packard CJ, Samani NJ: Telomere length, risk of coronary heart disease, and statin treatment in the West of Scotland Primary Prevention Study: a nested case-control study. Lancet 2007;369:107-114.

24 Fitzpatrick AL, Kronmal RA, Kimura M, Gardner JP, Psaty BM, Jenny NS, Tracy RP, Hardikar S, Aviv A: Leukocyte telomere length and mortality in the Cardiovascular Health Study. J Gerontol A Biol Sci Med Sci 2011;66:421-429.

25 Carrero JJ, Stenvinkel P, Fellstrom B, Qureshi AR, Lamb K, Heimburger O, Barany P, Radhakrishnan K, Lindholm B, Soveri I, Nordfors L, Shiels PG: Telomere attrition is associated with inflammation, low fetuinA levels and high mortality in prevalent haemodialysis patients. J Intern Med 2008;263: 302-312. 